\title{
Surface morphology of the central macrophages of erythroblastic islets in the spleen of aged and pregnant mice: an immunohistochemical light microscopic study*
}

\author{
Yuji Sonoda and Kazunobu Sasaki \\ Department of Anatomy, Kawasaki Medical School, Kurashiki, Japan
}

\begin{abstract}
Summary. This study used $100-\mu$ m thick paraffin sections stained by the ER-HR3 antibody to examine the three-dimensional surface morphology of the central macrophages of erythroblastic islets in the splenic red pulp of aged and pregnant mice. The ER-HR3-positive cells were the macrophages located at the center of the erythroblastic islets, and the number per unit of splenic area was almost constant until 30 days of age, thereafter showing a marked decrease. In pregnant females, the ER-HR3-positive macrophage number significantly increased and became approximately eight times higher than the control value. In aged virgin females, the islet macrophages were generally ovoid in cell profile, and shallow cup-shaped dents were formed on their cell surface. However, in pregnant females, the macrophages became larger in size, and cell socket structures, formed by long finger-like cytoplasmic processes, became prominent on their cell surface. The 3-D images, obtained from $100-\mu \mathrm{m}$ thick paraffin sections, provided the clear morphological evidence of the activity of the islet macrophages in spleen erythropoiesis.
\end{abstract}

Received February 25, 2008

* This work was supported in part by Research Project Grants from Kawasaki Medical School (No. 18-215T, 2006; 19204Y, 2007) and by a grant from the Ryobi Teien Memory Foundation (2007).

Address for correspondence: Dr. Yuji Sonoda, Department of Anatomy, Kawasaki Medical School, 577 Matsushima, Kurashiki, 701-0192 Japan

Tel: +81-86-462-1111, Fax: +81-86-462-1199

E-mail: ysonoda@med.kawasaki-m.ac.jp

\section{Introduction}

The mouse spleen red pulp is a hematopoietic tissue, being mainly involved in erythropoiesis, and contains numerous erythroblastic islets as a morphological hematopoietic unit (Brendolan et al., 2007). The islets consist of a central macrophage with erythroblasts around it (Bessis and Breton-Gorius, 1962; Fruhman, 1970; Bernard, 1991). Studies on hematopoiesis of the red pulp have revealed that aging, pregnancy and hormone treatment with estrogen and erythropoietin have a significant influence on erythropoiesis (Sasaki and Ito, 1981; Sasaki et al., 1981; Wojchowski et al., 2006). Compared with studies on the erythroblasts in the red pulp, however, less attention has been paid to the islet macrophages. Since the central macrophages are tightly surrounded by hematopoietic cells, scanning electron microscopy is not suitable for observation of the central macrophage surface. ER-HR3 is a rat-anti-mouse macrophage monoclonal antibody known to recognize macrophages associated with erythropoiesis in the bone marrow and the spleen (de Jong et al., 1994). The present study used ER-HR3 anti-macrophage monoclonal antibodies to clarify the surface morphology of the islet macrophages in the splenic red pulp of aged and pregnant mice.

\section{Materials and Methods}

ICR virgin female mice and pregnant mice were sacrificed at $1,20,30,50,70,100$, and 114 days of age. A total of 40 mice were used. In the pregnant group, five females were mated overnight at 100 days of age, and sacrificed at 14 days after copulation. The removed spleens were fixed in $4 \%$ paraformaldehyde in a $0.1 \mathrm{M}$ phosphate buffer $(\mathrm{pH}$ 
$7.4,4^{\circ} \mathrm{C}$ ) for $4 \mathrm{~h}$ for paraffin embedding. Then they were cut into $4-\mu \mathrm{m}$ thick and $100-\mu \mathrm{m}$ thick sections for the following immunohistochemical procedures.

\section{Immunohistochemistry}

Two rat anti-mouse macrophage monoclonal antibodies were used. One was ER-HR3 (Funakoshi, Japan), a marker of macrophages associated with erythropoiesis; the other, F4/80 (Cosmobio, Japan) serves as a panmacrophage marker. The avidin-biotin complex method (Vectastain Elite ABC kit; Vector Laboratories, USA) was employed as follows. Sections were treated with $99 \%$ methanol containing $0.3 \% \mathrm{H}_{2} \mathrm{O}_{2}$ for 30 min, after which they were immersed in $0.1 \%$ normal rabbit serum in phosphate-buffer saline $(\mathrm{pH} 7.6)$ for $1 \mathrm{~h}$ at $37^{\circ} \mathrm{C}$. Then the sections were incubated either in F4/80 (dilution 1:250) or ER-HR3 (dilution 1:150) for two hours at $37^{\circ} \mathrm{C}$. After incubation in the primary antibodies, the sections were treated with biotinylated anti-rat IgG antibody for 30 min, and then immersed in an $\mathrm{ABC}$ reagent for $30 \mathrm{~min}$. For visualization of the immunoreactions, $0.02 \% 3,3^{\prime}$ diaminobenzidine, containing $0.005 \%$ hydrogen peroxide and $50 \mathrm{mM}$ Tris-HCl buffer (pH 7.6), was used. For negative controls, sections were reacted with $0.1 \%$ normal rabbit serum albumin instead of the primary antibodies.

Immunostained sections, $4-\mu \mathrm{m}$ thick, were counterstained with hematoxylin, and the numbers of ERHR3-positive cells and F4/80-positive cells per unit area $\left(1 \mathrm{~mm}^{2}\right)$ in the spleen were calculated from photographs at a final magnification of $\times 500$. The mean cell numbers \pm SD were obtained at each day of age. The cell numbers of pregnant females were compared with those of the virgin control at 114 days of age. The values obtained were statistically evaluated by Student's t-test.

\section{Three-dimensional reconstruction}

To obtain three-dimensional profiles of macrophages, computer-aided reconstructions were carried out. Serial digital images of ER-HR3-positive macrophages in $100-\mu \mathrm{m}$-thick immunostained sections were obtained at $0.5 \mu \mathrm{m}$ intervals by light microscopy with a computer controlled z-axis stepping motor (Mitani Co., Japan). After enhancement with IPLab software (Scanalytics, USA) followed by noise reduction with AutoDeblur software (AutoQuant, USA), macrophage outlines were traced with Adobe Photoshop software (Adobe Systems Inc., USA). The total number of serial profile images per one macrophage was 90 to 120 . DeltaViewer software (freeware donated by Prof. Masaaki Wada, Department of Information and Computer Sciences, Nara Women's
University, ver. 2.0.8) was used for three-dimensional reconstructions.

These experiments were approved by the Animal Research Committee of Kawasaki Medical School (No. 06-053) and conducted according to the "Guide for the Care and Use of Laboratory Animals" of that institution.

\section{Results}

\section{ER-HR3-positive cells in the splenic red pulp of virgin and pregnant females}

The splenic tissue at one day of age was mostly composed of the erythropoietic red pulp, in which a large number of ER-HR3-positive cells were widely scattered (Fig. 1a). The neonatal red pulp contained numerous erythroblastic islets as histological erythropoietic units, and the ERHR3-positive cells, approximately $40 \mu \mathrm{m}$ along the long axis, were generally located at the center of an erythroblast cluster, extending their long cytoplasmic processes among surrounding erythroblasts (Fig. 1b). In the aged virgin mice, the number of erythroblasts in the red pulp decreased (Fig. 1c), and a dramatic fall in the number of ER-HR3-positive macrophages was observed. At 114 days of age, these markedly diminished in cell size to approximately $25 \mu \mathrm{m}$ along the long axis (Fig. 1d).

Neonatal red pulp, stained by the F4/80 monoclonal antibody, contained numerous positive cells, and the positive cell number did not show any decrease in aged females at all.

In pregnant mice, the spleens became markedly enlarged and contained many more erythroblasts and ER-HR3-positive macrophages than did those in virgin females (Fig. 1e). The ER-HR3-positive macrophages were approximately $40 \mu \mathrm{m}$ along the long axis, and the cell profiles were as complex as those seen in neonatal red pulp. ER-HR3-immunostaining disclosed long cytoplasmic processes of the macrophages extending among surrounding erythroblasts (Fig. 1f).

\section{Quantitative observations of the ER-HR3-positive macrophages and F4/80-positive macrophages in virgin and pregnant females}

Postnatal changes in the spleen weight of the virgin females and the number of ER-HR3-positive cells per unit area are shown in Figure 2a. The weight was $8.2 \pm 4.0$ $\mathrm{mg}$ at one day of age, increasing rapidly to $91.1 \pm 6.3 \mathrm{mg}$ at 50 days of age, but thereafter remaining almost constant until 100 days of age. The number of ER-HR3-positive macrophages per unit splenic area was $853.1 \pm 62.1 / \mathrm{mm}^{2}$ 


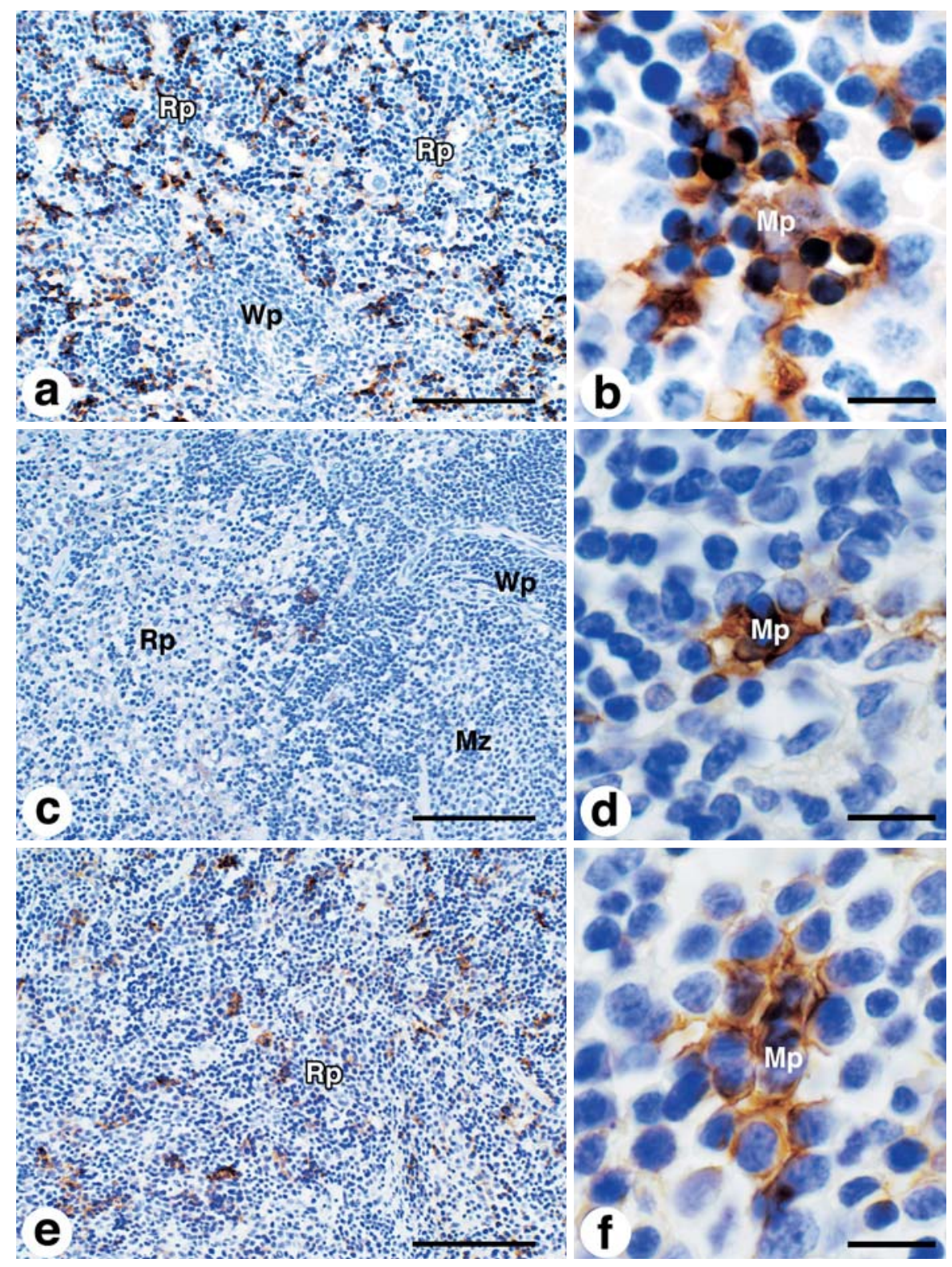

Fig. 1. ER-HR3-immunostained spleens. Counterstained with hematoxylin. a, b: One-day-old spleen. In a low magnification micrograph (a), ER-HR3-positive cells, stained dark brown, appear widely scattered throughout the red pulp (Rp). Wp: white pulp. An erythroblastic islet (b) composed of numerous erythroblasts with darkly stained nuclei surrounding ER-HR3-positive macrophages (Mp), has prominent long cytoplasmic processes. c, d: 114-day-old spleen of a virgin female. As shown in a low magnification micrograph (c), white pulp (Wp) increases in proportion in the splenic pulp. ER-HR3-positive cells are present in the red pulp (Rp), though very few in number. Mz: marginal zone. In d, an ER-HR3-positive macrophage (Mp) has an ovoid cell body with short cytoplasmic processes. A few erythroblasts are seen around it. e, f: 114-day-old spleen of a pregnant female at 14days of gestation. A low magnification micrograph (e) shows that the red pulp (Rp) raises the volume proportion and contains numerous ER-HR3-positive cells. At high magnification (f), the profile of the ER-HR3-positive macrophage (Mp) becomes large and extends long cytoplasmic processes among erythroblasts. Bars: $100 \mu \mathrm{m}(\mathrm{a}, \mathrm{c}, \mathrm{e}), 10 \mu \mathrm{m}(\mathrm{b}, \mathrm{d}, \mathrm{f})$. 

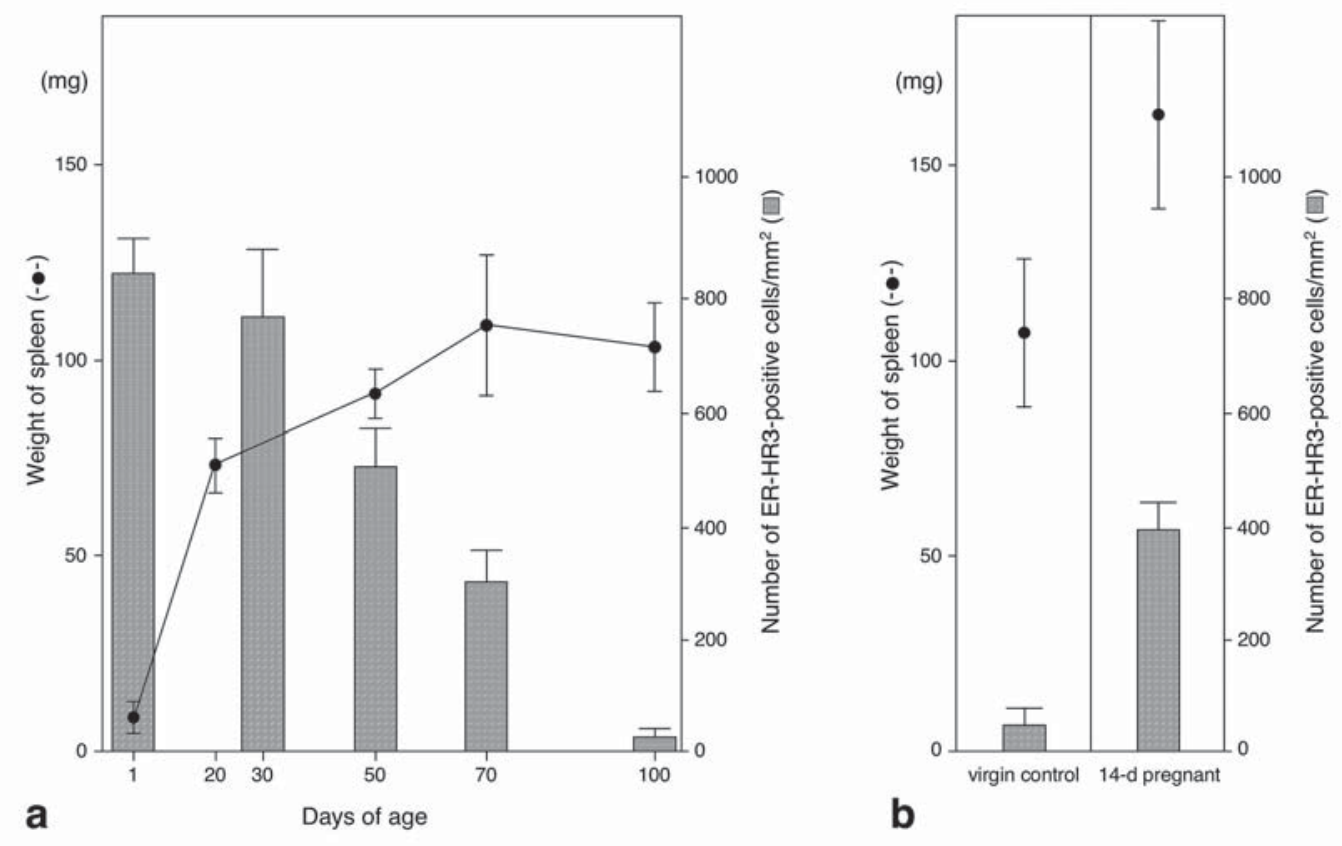

Fig. 2. Spleen weights and numbers of ER-HR3-positive cells per splenic unit area of virgin females (a) and pregnant females (b). The spleen weights are indicated by black circles (Mean \pm SD), and the columns show the number of ER-HR3-positive cells (Mean \pm SD). a: The spleen weights showed a rapid increase between one day of age and 50 days of age, and then the weights were almost constant. The numbers of ER-HR3-positive cells were almost constant until 30 days of age, and then the numbers showed a marked decrease. At 100 days of age, the number of positive cells became negligible. b: In the pregnant females, both the spleen weight and the number of ER-HR3-positive cells showed a rapid increase. There were as many as eight times more ER-HR3-positive macrophages in the pregnant red pulp than in the virgin controls at 114 days of age.

at one day of age, and the number slightly but significantly decreased from $775.0 \pm 120.3 / \mathrm{mm}^{2}$ at 30 days of age to $509.4 \pm 68.6 / \mathrm{mm}^{2}$ at 50 days of age $(\mathrm{p}<0.01)$. Then the cell number dramatically decreased to $25.0 \pm 14.0 / \mathrm{mm}^{2}$ at 100 days of age, approximately one thirty-fifth of the number at one day of age (Fig. 2a). Concerning the F4/80positive macrophage, the cell numbers per unit area were almost constant, $600-800 / \mathrm{mm}^{2}$, between one day and 100 days of age in virgin females.

As shown in Figure 2b, in the pregnant females at 14 days of gestation, the spleen weights were significantly higher than those of the virgin controls $(p<0.01)$. The number of ER-HR3-positive macrophages per unit area also significantly increased to $396.9 \pm 50.1 / \mathrm{mm}^{2}$, becoming approximately eight times higher than the control value, $46.9 \pm 31.3 / \mathrm{mm}^{2}$, of the 114 -day-old females $(\mathrm{p}<0.01)$.

\section{Computerized 3-D reconstruction of the ER-HR3- positive macrophages of control and pregnant mice obtained from 100- $\mu$ m sections}

In the red pulp of the control virgin females, ERHR3-positive macrophages were ovoid in cell profile, approximately $30 \mu \mathrm{m}$ along the long axis, and on their cell surface, shallow cup-shaped dents had formed (Fig. $3 \mathrm{a}, \mathrm{b})$. Spike-like short projections, less than $1 \mu \mathrm{m}$ long, were seen at the rim of the dents. Erythroblasts were seen around the macrophages - albeit few - and they appeared to have cell contacts with the central cells just on the shallow dents (Fig. 3b).

At 14 days of gestation, the ER-HR3-positive macrophages became larger in size, approximately $45 \mu \mathrm{m}$ along the long axis, and numerous cytoplasmic processes were found on their cell surface (Fig. 3c). Instead of 

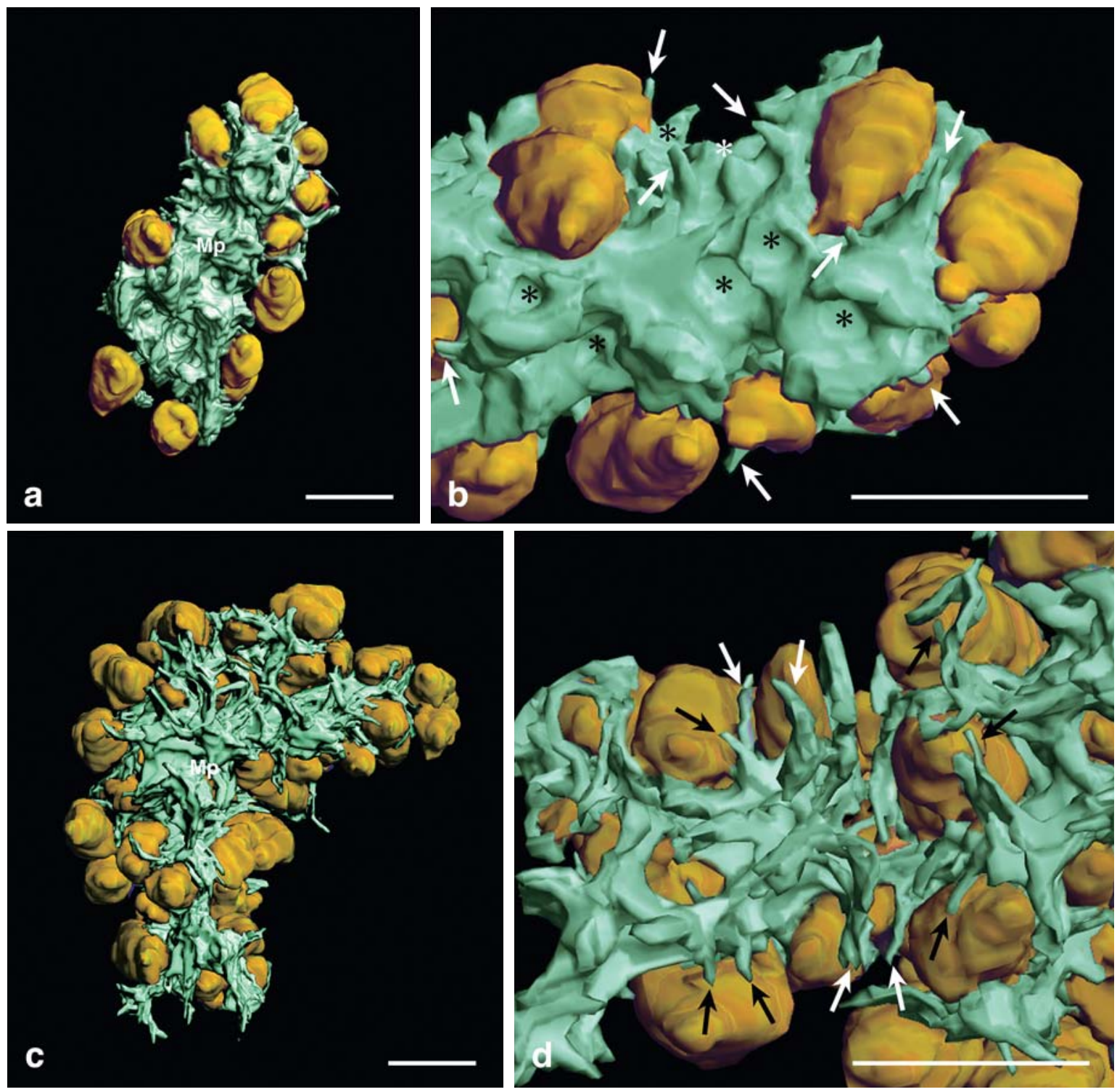

Fig. 3. Erythroblastic islets of virgin $(\mathbf{a}, \mathbf{b})$ and pregnant $(\mathbf{c}, \mathbf{d})$ mice. The central macrophages are shown in green, and the erythroblasts in yellow. To show details of the cytoplasmic processes of the macrophages, the erythroblasts in front of the cells were removed, and - in high magnification images, (b) and (d) - the central macrophages are slightly rotated. Bars: $10 \mu \mathrm{m}$. a, b: An erythroblastic islet of a control virgin mouse at 114 days of age. A few shallow dents $(*)$ are observed on the macrophage surface. The erythroblasts appear to be just on the shallow cup-shaped dents of the macrophage. Arrows in b show spike-like processes. c, d: An erythroblastic islet of a pregnant female mouse. Numerous finger-like processes, indicated by arrows in d, extend from the rim of deep hemispherical dents of the central cell to surrounding erythroblasts. 
shallow dents, cell socket structures, formed by well developed cytoplasmic processes and deep hemispherical dents, could be observed. These cell socket structures, approximately $7 \mu \mathrm{m}$ in diameter, covered the entire cell surface of the central cells, and numerous long finger-like processes, $3 \mu \mathrm{m}$ long, extended from the rim of the dents. Erythroblasts were located in the cell sockets (Fig. 3c) and were tightly held by the finger-like cytoplasmic processes (Fig. 3d).

\section{Discussion}

The present study revealed that the number of splenic erythroblastic islets markedly decreases in aged mice but significantly increases in pregnancy. In the latter case, the islet macrophages also rapidly increase in cell size, and their cytoplasmic processes rapidly extend to hold the erythroblasts tightly on the cell surface.

The ER-HR3 used in the present study is a rat-antimouse macrophage monoclonal antibody which was initially introduced as an antibody against two kinds of cell membrane proteins of bone marrow-derived hematopoietic reticulum cells by de Jong et al. (1994). This antigen is known to be expressed on macrophages associated with erythropoiesis in the bone marrow and the spleen (de Jong et al., 1994), while the antigen F4/80 is a pan-macrophage marker introduced by Taylor $e t$ al. (2005). Regarding the macrophage sub-population, the spleen red pulp is known to contain two different groups: the first are central macrophages of erythroblastic islets, and the other are scavenger macrophages which remove senescent erythrocytes from blood peripheral circulations (Simon, 1980; Mebius and Kraal, 2005). Our results show that, for postnatal changes in positive cell numbers, there existed marked differences between F4/80 staining and ER-HR3 staining, suggesting that our quantitative studies of ER-HR3-positive macrophages specifically reflect the changes in the erythropoietic activity of the spleen.

The present study clearly revealed the 3-D structure of the central macrophages of erythroblastic islets both in control virgin and pregnant mouse spleens by computerized reconstruction of $100-\mu \mathrm{m}$ sections. The central macrophages have characteristic cytoplasmic processes on their cell surface, and the function of the cell socket-like structures formed by those processes is not for phagocytosis but rather to maintain a firm grasp on the erythroblasts on the central cell surface (Sasaki and Iwatsuki, 1997). In our previous studies, long fingerlike processes were not observed on the surface of scavenger macrophages but were specifically identified on the surface of the erythroblastic islet cells. In the erythroblastic islets, it is suggested that cell adhesion between VCAM-1 on the central macrophages and VLA4 on erythroid cells is important for preventing apoptosis of the erythroid cells during the erythroblast maturation (Sadahira and Mori, 1999). Thus, the appearance of numerous finger-like processes on the central macrophages may be involved in such interaction between macrophages and erythroblasts during erythropoiesis in the spleen. Our 3-D images of numerous finger-like cytoplasmic processes in the pregnant mouse spleen provided clear morphological evidence of the increased activity of the central macrophages in erythropoiesis.

Erythroblastic islets are morphological units of erythropoiesis not only in the spleen but also in the bone marrow. Using $100-\mu \mathrm{m}$-thick immunostained paraffin sections, we previously reported the presence of a threedimensional surface structure of islet cells in both the fetal liver and the neonatal bone marrow (Sonoda and Sasaki, 2006; Notsu et al., 2007). The central macrophages of the erythroblastic islets in the fetal liver possessed cell socket structures formed by finger-like processes and deep hemispherical dents on the cell surface (Sasaki and Iwatsuki, 1997; Sonoda and Sasaki, 2006). On the other hand, the central macrophages in the neonatal bone marrow were characterized by thin cord-like projections for each erythroblast to twine around them, and cell socket structures were not observed on the central cell surface (Notsu et al., 2007). These findings indicate that the three-dimensional surface structure of the central cells of the erythroblastic islets differ considerably with respect to hematopoietic tissues. These morphological differences might be closely associated with their cell origins and also related to the erythropoietic activity in the different tissues.

\section{Acknowledgments}

The authors wish to thank Mr. K. Uehira and Mr. T. Suda for their skillful technical assistance.

\section{References}

Bessis MC, Breton-Gorius J: Iron metabolism in the bone marrow as seen by electron microscopy: a critical review. Blood 19: 635-663 (1962).

Bernard J: The erythroblastic island: past and future. Blood Cells 17: 5-10 (1991).

Brendolan A, Rosado MM, Carsetti R, Selleri L, Dear TN: Development and function of the mammalian spleen. Bioessays 29: 166-177 (2007). 
Fruhman GJ: Splenic erythropoiesis. In: Regulation of hematopoiesis (Gordon AS, ed), Appleton-CenturyCrofts, New York, 1970 (p. 339-368)

de Jong JP, Voerman JS, van der Sluijs-Gelling AJ, Willemsen R, Ploemacher RE: A monoclonal antibody (ER-HR3) against murine macrophages. I. Ontogeny, distribution and enzyme histochemical characterization of ER-HR3-positive cells. Cell Tissue Res 275: 567-576 (1994).

Mebius RE, Kraal G: Structure and function of the spleen. Nat Rev Immunol 5: 606-616 (2005).

Notsu E, Sonoda Y, Sasaki K: A histological study and three-dimensional reconstruction of F4/80-positive reticular cells and macrophages at the onset of murine bone marrow hematopoiesis (Japanese with English abstract). Kaibougaku Zasshi 82: 53-60 (2007).

Sadahira Y, Mori M: Role of the macrophage in erythropoiesis. Pathol Int 49: 841-848 (1999).

Sasaki K, Ito T: Effects of estrogen and progesterone on the spleen of the mouse: A light and electron microscopic study. Arch Histol Jap 44: 203-213 (1981).

Sasaki K, Matsumura G, Ito T: Effects of pregnancy on erythropoiesis in the splenic red pulp of the mouse: A quantitative electron microscopic study. Arch Histol Jap 44: 429-438 (1981).
Sasaki K, Iwatsuki H: Origin and fate of the central macrophages of erythroblastic islands in the fetal and neonatal mouse liver. Microsc Res Tech 39: 398-405 (1997).

Simon GT: Splenic macrophages. In: The reticuloendothelial system (Carr I, Daems WT, ed). Plenum Press, New York, 1980 (p. 469-497)

Sonoda Y, Sasaki K: Three-dimensional surface structure of macrophages in fetal and adult mouse liver: an immunohistochemical light microscopic study. Cells Tissues Organs 184:166-171 (2006).

Taylor PR, Martinez-Pomares L, Stacey M, Lin HH, Brown GD, Gordon S: Macrophage receptors and immune recognition. Annue Rev Immnol 23: 901-944 (2005).

Wojchowski DM, Menon MP, Sathyanarayana P, Fang J, Karur V, Houde E, Kapelle W, Bogachev O: Erythropoietin-dependent erythropoiesis: New insights and questions. Blood Cells Mol Dis 36: 232-238 (2006). 